\title{
Remarkable but not so unusual
}

\author{
The Comet Sweeper: Caroline Herschel's \\ Astronomical Ambition \\ by Claire Brock \\ Icon Books: May 2007. 208 pp. £9.99
}

\section{Judith P. Zinsser}

Dava Sobel and Patricia Fara have proved that there is an audience for popular yet scholarly stories of the adventures of scientists at the beginning of the modern age. Claire Brock's brief study of the astronomer Caroline Herschel (1750-1848) intends to please these same readers. The easy prose of The Comet Sweeper is laced with quotations from Herschel's two autobiographies and her astronomical diaries. All the important facts of this interesting woman's life - from her youth in the German principality of Hanover in the late eighteenth century to her work with her astronomer brother, William - are here. Brock describes Herschel's considerable accomplishments, which included the discovery of comets and nebulae and the publication of two extensive astronomical guides: a revised edition of John Flamsteed's Historiae Coelestis, a catalogue of the 'fixed stars' and the standard authority on the heavens, and a catalogue of star clusters and nebulae, a similar listing that she and her brother made from their meticulous nightly sweeps of the sky.

Unfortunately, Brock has an agenda that leads her into some of the pitfalls often encountered by biographers of famous women in history. Brock describes her task as "rehabilitating Caroline Herschel". She criticizes historians whom she feels acknowledged Herschel's dis-

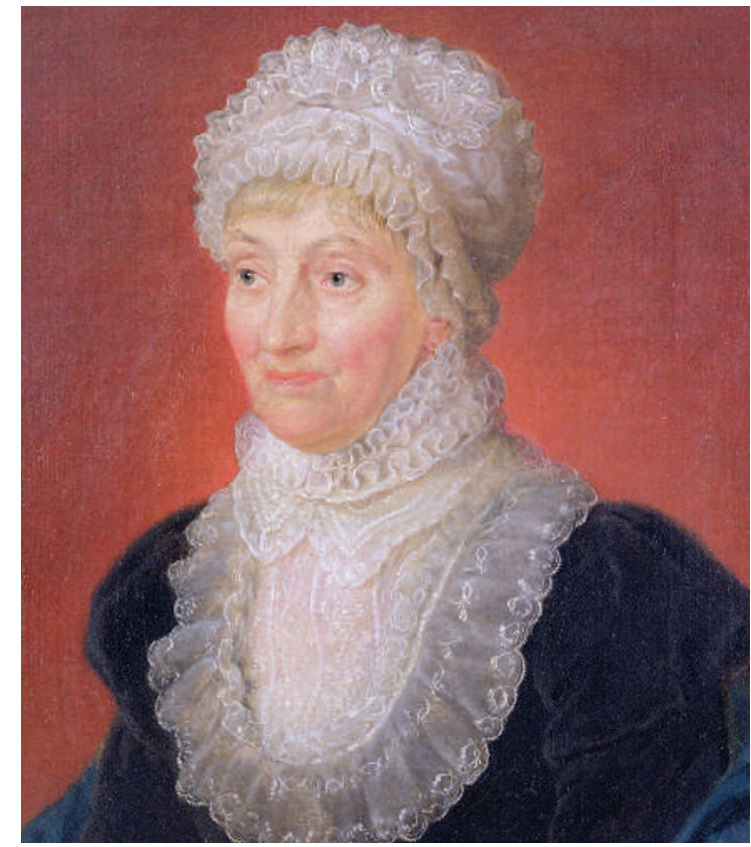

Caroline Herschel discovered comets and nebulae.

coveries but did not give proper attention to the astronomer's considerable ambition and desire for "independence". Brock wants to prove that Herschel was not the dutiful daughter and sister usually portrayed, but an autodidact struggling against the constraints of her day. This leads Brock to overdramatize these constraints, to comb Herschel's personal writings for hints of rebellion and to offer mismatched psychological interpretations.

Herschel was certainly as disadvantaged as any younger sister in a large family - she was one of ten children $\stackrel{m}{=}$ — of no particular education or rank and with limited financial resources. Disfigured by smallpox 綮 as a young child, with no hope of $\frac{\mathrm{O}}{\mathrm{c}}$ a dowry from her musician father and no gift for women's trades, despite some lessons from a milliner, it was not a cruel mother, as Brock suggests, that left Herschel with little prospect of marriage or respectable employment outside the household. Her brother William must have felt he was providing generously for his unfortunate sibling by bringing her to England to run his household, allowing her to sing with his choir and to copy their musical scores.

Brock acknowledges that Herschel often wrote of her desire to be "useful" and that she defined this utility within the confines of service to her family. When William trained her to become his assistant in his newfound avocation for astronomical observation, he gave her no independence, but he did give her the means to scientific accomplishment and fame. Without William, there would have been no discoveries and no recognition.

The root of the problem with the way Brock has chosen to frame her biography may be that although Herschel indeed deserves her fame, her life was not so unusual for the times. Brock writes that Herschel grew up "exploited

\section{EXHIBITION \\ Famous faces}

This arresting portrait of Nobel prizewinner Harold Varmus is one of many images of scientific luminaries by Mariana Cook on public display in the Faces of Science exhibition at the US National Academy of Sciences in Washington DC until 30 September.

Cook, who studied with the pioneering nature photographer Ansel Adams, hopes to "humanize" scientists through her work, to illuminate individual characters and explore possible commonalities.

Each portrait is paired with a short essay explaining how the subject became drawn to his or her chosen field - as in Cook's book of the same name (W. W. Norton, 2005). Other leading researchers captured in iconic shots include $\mathrm{E}$. O. Wilson, Elizabeth Blackburn and Frederick Sanger.

Wilson sits beatifically in a pile of autumn leaves; Sanger smiles beneath an orchid. Sitters such as these share "an elasticity of mind uncommon to most of us", Cook has said. Collections of her photographs are also held by the Museum of Modern Art and the Metropolitan Museum of Art in New York.

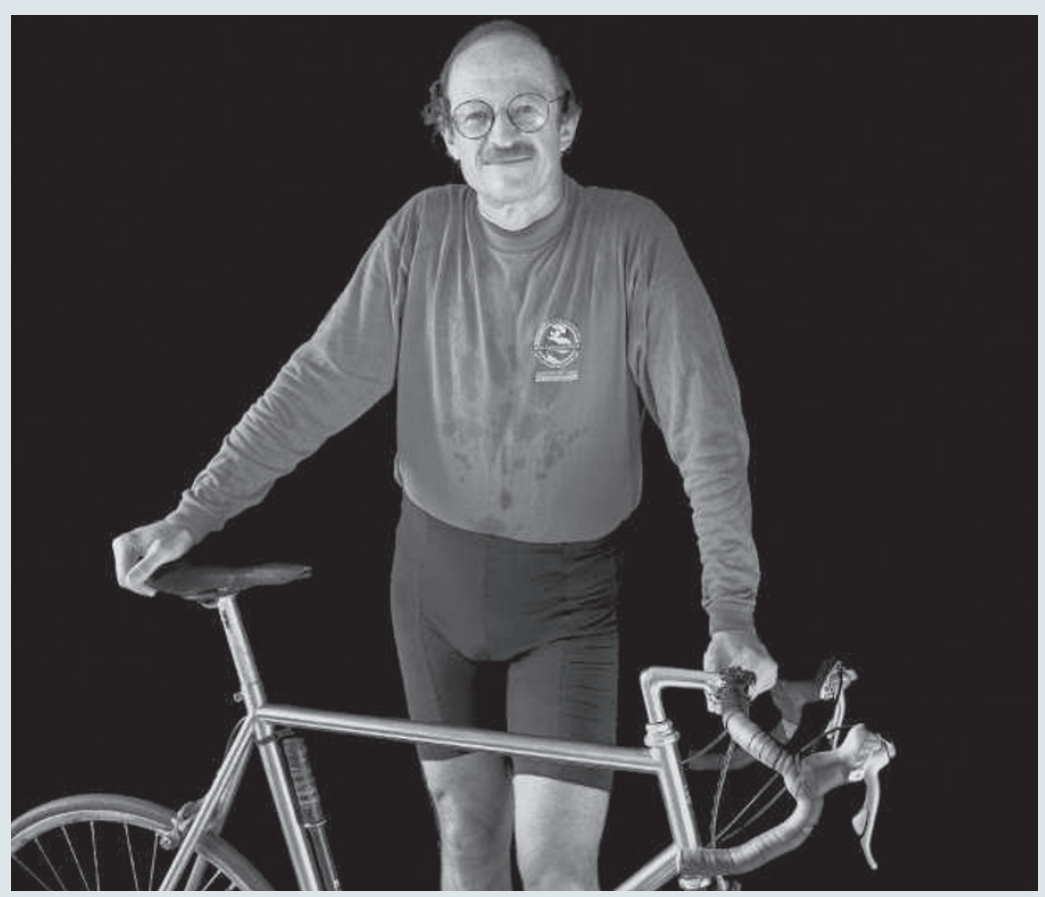


and enslaved" by the drudgery of housework. Brock characterizes a father's caution not to expect an offer of marriage as "obviously" having a "devastating impact" on the young girl. European women's history shows us that Herschel was neither enslaved nor devastated but, like other women of accomplishment, made the best of her circumstances. Earlier in the eighteenth century the women of the famous Winkelmann family of Prussian astronomers also had the patience and skill to watch the stars for hours at a time, and to record their observations with care. In this exciting period of early modern science, amateurs, whether female or male, if in the right place at the right time, could make significant contributions to knowledge.

I wish that Brock had let go of the rehabilitation project and focused instead on the richness of Herschel's autobiographies, which she does recognize. They have already been edited by Michael Hoskin, an eminent historian of astronomy, but Brock, with her literary training, has an excellent eye for the vivid quotation. An analysis of the two versions of her past that this remarkable woman created in her old age would make a fascinating double journey from eighteenthcentury Hanover to Bath to Windsor, and back to Hanover 50 years later - revealing what Herschel herself chose to illuminate, cloud, or hide altogether.

Judith P. Zinsser is author of the recently published La Dame d'Esprit: A Biography of the

Marquise Du Châtelet and is a professor of history at Miami University, Oxford, Ohio 45056, USA.

\section{EXHIBITION}

\section{Palaeontology meets Hanna-Barbera}

\author{
The Homo species \\ by Hyungkoo Lee \\ Korean Pavilion, 52nd Venice Biennale, \\ Venice, Italy \\ (until 21 November)
}

\section{Colin Martin}

Korean artist Hyungkoo Lee's quirky take on palaeontology is a showstopper among the acres of international contemporary art on offer at the 52nd Venice Biennale. Lee, the first artist to have a solo show in his country's pavilion, immediately grabs the attention of visitors with a dramatically spotlit moment from the world's geological past, staged in the centre of a darkened room. The skeleton of a predator, pouncing on its transfixed, smaller prey, initially evokes the natural history tableaux encountered in museums. Closer examination reveals that the exaggerated quality of Lee's tableau owes more to cartoon animators William Hanna and Richard Barbera than to palaeontologists. Reading the exhibit titles, Mus Animatus and Felis Catus [sic] Animatus, confirms that we're looking at Tom and Jerry, caught in their perpetual cycle of tragedy narrowly averted, with Jerry outwitting Tom to escape in the nick of time. This work is part of Lee's Animatus series, in which he "explores hypothetical anatomical possibilities of beings without existential evidence".

By exploring two layers of unreality, Lee achieves a double deception. He transforms familiar animated two-dimensional cartoon characters, which we know to be unreal, into intricately realized three-dimensional 'fossils' created from his imagination. He might give the appearance of working in a quasi-scientific manner but, unlike palaeontologists, he fakes the fossilized remains he uses. "Merely seeing Lee's work gives no clues to the complexity of its creation," comments Asian art specialist Howard Rutkowski. In this exhibition, however, Lee carefully documents his working methods and displays this evidence of his deception throughout the pavilion, as a

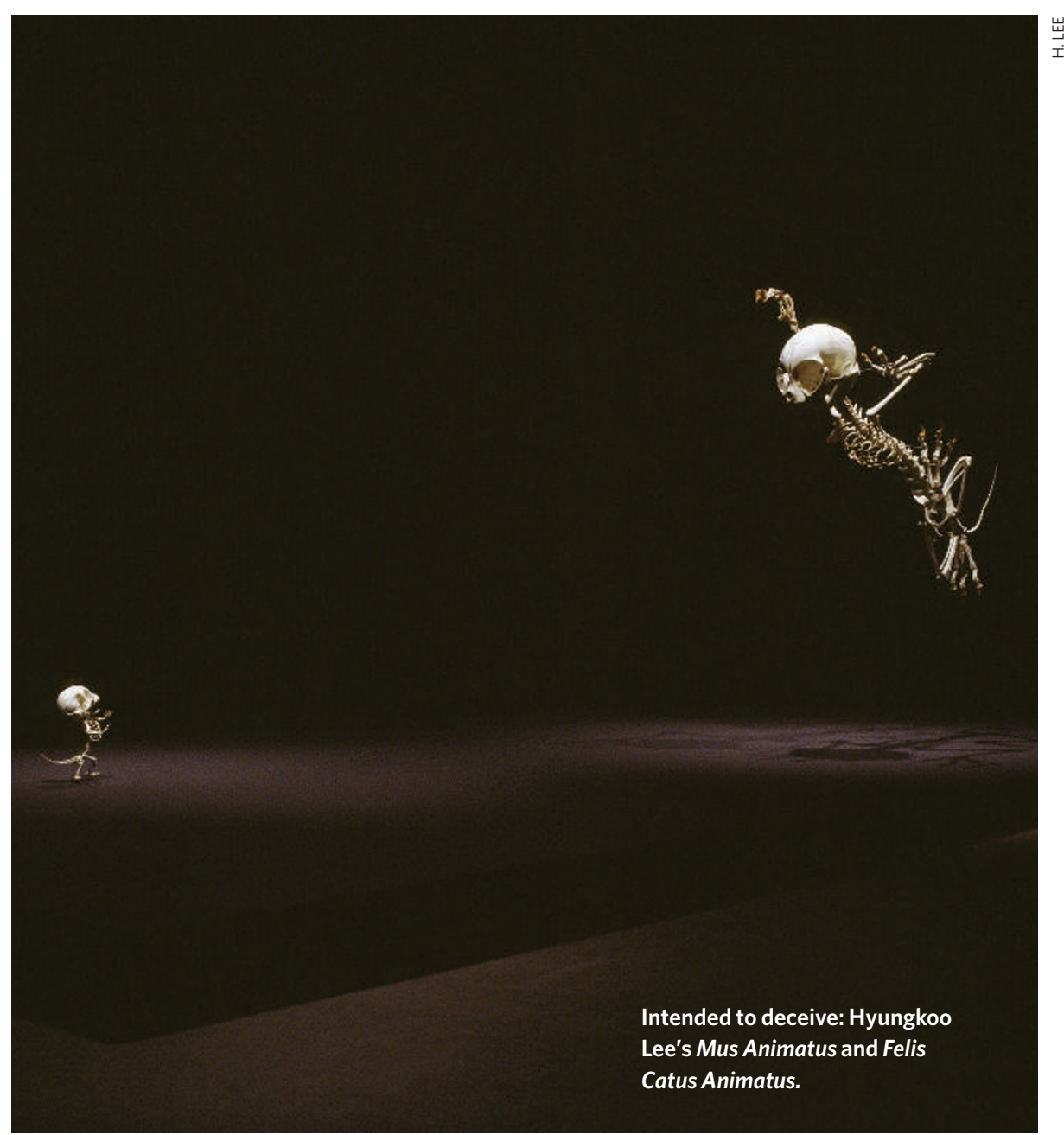

context for viewing his finished works.

In an adjacent room, Lee reveals his artistic sleight of hand in a semicircular vitrine that contains bones of real animals, various implements, anatomical drawings of real animals and their animations, chemicals, modelling tools and fake bones. The assorted tools and chemicals not only emphasize the artist's intention to deceive, but also beseech the viewer to believe anyway. A large black-and-white photograph also evokes scientific research by showing technicians in white coats in a laboratory. It is obviously staged, however, and they are pouring plaster into moulds to create the fake fossils. Lee's jokes and stories involve narrative build-up before revealing their punch lines. $\mathrm{He}$ works backwards, showing us the denouement first and then revealing what preceded it, like a cartoon screened in reverse.

Colin Martin is a writer based in London. 